\title{
Substrate heating method for coating metal surfaces with high-silica zeolites: ZSM-5 coatings on stainless steel plates
}

\author{
Melkon Tatlier ${ }^{\mathrm{a}, *}$, Mesut Demir ${ }^{\mathrm{a}}$, Begüm Tokay ${ }^{\mathrm{a}}$, \\ Ayşe Erdem-Şenatalar ${ }^{a}$, Lioubov Kiwi-Minsker ${ }^{b}$ \\ a Department of Chemical Engineering, Istanbul Technical University, Maslak, 34469 Istanbul, Turkey \\ ${ }^{\mathrm{b}}$ Ecole Polytechnique Fédéral de Lausanne (LGRC-EPFL), CH-1015 Lausanne, Switzerland
}

Received 12 May 2006; received in revised form 25 November 2006; accepted 30 November 2006

\begin{abstract}
Syntheses of ZSM-5 coatings on stainless steel plates were carried out via the substrate heating method. The reaction mixture was kept at temperatures below $100{ }^{\circ} \mathrm{C}$, while the metal plates were heated to temperatures above $100{ }^{\circ} \mathrm{C}$. It was demonstrated that continuous ZSM-5 coatings of different textures with different crystal morphologies and void fractions could be formed. ZSM-5 coatings were characterized by X-ray diffraction and scanning electron microscopy. The thickness of the ZSM-5 coatings could be varied depending on the synthesis conditions. Besides providing the opportunity of manipulating coating properties, the method is also beneficial in respect to the synthesis duration as compared to the conventional procedures.
\end{abstract}

(C) 2006 Elsevier Inc. All rights reserved.

Keywords: Zeolites; Coatings; ZSM-5; X-ray diffraction; Scanning electron microscopy

\section{Introduction}

Different materials coated by zeolites are desired for applications related to adsorption, catalysis, ion-exchange, etc. They may serve as membranes in separation processes $[1,2]$, as structured catalysts in reactors minimizing the pressure drop and mass transfer limitations [3,4], as sensors [5], and adsorbents in adsorption heat pumps [6]. Zeolite coatings may be prepared by a variety of synthesis procedures, resulting in coatings of different characteristics. Variations may occur in the thickness, orientation and homogeneity of the zeolite films.

Thin, uniform and continuous zeolite films are required for some specific applications like membrane separations. A well-known approach, which may be used for this purpose, involves the formation of a monolayer of tiny colloidal crystals by a surface charge reversal followed by

\footnotetext{
${ }^{*}$ Corresponding author.

E-mail address: tatlierm@itu.edu.tr (M. Tatlier).
}

hydrothermal treatment [7]. Orientation of the crystals on the surface may also be important depending on the pore structure of the zeolite. Various studies have been performed recently that may lead to significant improvement in the preferred orientation of zeolite films. The preparation of b-oriented MFI membranes by growing the crystals of an oriented seed layer to a well-intergrown film [8], the preparation of mesoporous silica layers on substrates and the subsequent synthesis of b-oriented MFI films on these intermediate layers by in situ crystallization [9] or by the secondary growth of oriented seed monolayers attached to these mesoporous layers [10] as well as the preparation of a-oriented MFI membranes by secondary growth from an a-oriented monolayer of MFI seeds [11] should especially be mentioned in this respect. For some other applications related to adsorption or catalysis, thickness of the coatings may be crucial for optimal performance, while continuous and defect-free formation may not be very important.

The substrate heating method, may allow a better manipulation of zeolite synthesis by controlling the temperature of the metal substrate and the temperature of the 
bulk reaction mixture, separately [12]. The method allows extended growth of the zeolite film on the support materials as compared to the conventional synthesis, thus making the preparation of thicker films possible. Thin and continuous films may also be readily prepared. In this method, the metal is heated directly while the reaction mixture is kept at a lower temperature. Due to a temperature difference between the reaction mixture and the substrate, the crystallization in the bulk is suppressed, while being promoted on the metal surface. In this manner, the phase transformations of the metastable zeolites can be delayed for long periods of time, depending on the volume of the reaction mixture. Thick zeolite A coatings could be obtained by the substrate heating method, which were not possible to prepare by conventional one-step methods [12]. The coatings exhibited a sponge-like structure favoring diffusion within these materials.

Zeolites with low $\mathrm{Si} / \mathrm{Al}$ ratios, like types $\mathrm{A}$, $\mathrm{HS}$ and $\mathrm{X}$, can be obtained at relatively low temperatures $\left(<100^{\circ} \mathrm{C}\right)$, while zeolites with high Si/Al ratios, like ZSM-5 and Beta, require temperatures higher than $100^{\circ} \mathrm{C}$. Autoclaves are required to synthesize these high-silica zeolites as well as their coatings. The preparation of coatings of MFI-type (ZSM-5 and Silicalite-1) phases is warranted due to the unique properties of these zeolites for catalysis and separation applications [13-15].

Up to now, only coatings of zeolites A, HS and P at relatively low temperatures have been prepared by the substrate heating method $[12,16]$. Application of this method for the synthesis of coatings of high-silica zeolites may especially allow the practical preparation of thicker films suitable for some important applications. Herein, we report for the first time the preparation of ZSM-5 coatings on metal plates by the substrate heating method. A special sealed reactor was constructed for this purpose, allowing variations in synthesis conditions.

\section{Experimental}

The substrate heating method was originally developed for growing zeolite coatings preferentially on metal substrates, by suppressing the zeolite formation in the bulk solution [12]. The substrate is heated in this method, from one side, keeping the substrate temperature higher than the solution temperature, which is controlled by a water/oil thermostat. Coatings of low-silica zeolites could be obtained at relatively low temperatures: zeolite A coatings were obtained with a metal surface temperature of about $60{ }^{\circ} \mathrm{C}$ and a solution temperature of $25^{\circ} \mathrm{C}$. In this case, evaporation from the solution generally does not present a significant problem. In this study, for preparing coatings of high-silica zeolites, the synthesis solution was kept at temperatures below $100{ }^{\circ} \mathrm{C}$, but the temperature of the metal plate had to be kept at temperatures quite higher than $100^{\circ} \mathrm{C}$. Therefore, the system was sealed tightly to prevent any evaporation from the solution, especially in the vicinity of the metal plate to keep the composition of the reaction mixture constant during the synthesis.

The synthesis experiments were carried out in an oil thermostat at temperatures $<100{ }^{\circ} \mathrm{C}$. The system shown in Fig. 1 consisted of a stainless steel vessel $(150 \mathrm{ml})$ with a cover and a soldering resistance $(100 \mathrm{~W})$ attached to the latter. The cover had an extension, which was immersed into the vessel filled with the synthesis solution. The resistance inserted into this extension was utilized to heat preferentially the bottom of the metal cover extension, at the lower end of which a stainless steel plate $\left(10 \times 10 \times 0.5 \mathrm{~mm}^{3}\right)$ was placed horizontally. The additional unnecessary heating of the system components, except for the stainless steel plate on which synthesis took place, was prevented by insulating the heating resistance with teflon. It was determined that the temperatures of the other metal parts of the device were not much affected by the heating resistance and the temperature of the bulk of the synthesis solution stayed at a value almost equal to that of the oil bath, which was kept at $90^{\circ} \mathrm{C}$. The temperature of the resistance was measured by a thermocouple during the synthesis experiments. The temperature of the substrate could not be measured directly under the conditions of synthesis. From measurements performed separately, the surface temperature of the substrate was estimated to be around $120^{\circ} \mathrm{C}$ and $135^{\circ} \mathrm{C}$, when the oil bath was kept at $90^{\circ} \mathrm{C}$ and the temperature of the resistance was equal to $240{ }^{\circ} \mathrm{C}$ and $280^{\circ} \mathrm{C}$, respectively. The temperature of the substrate, which was immersed in water, was measured from the side just remaining under the plate holder ( 8 in Fig. 1). It should be noted that these measured values are only approximations of the substrate surface temperature and the actual temperature of the substrate surface might change to some extent as the thickness of the coating increases.

Prior to the synthesis of the zeolite coatings, the stainless steel (AISI 316 grade) plates were cleaned as reported elsewhere [17]. Synthesis experiments were carried out in a clear solution with the composition of 250TPAOH: $400 \mathrm{Na}_{2} \mathrm{O}: \mathrm{Al}_{2} \mathrm{O}_{3}: 1200 \mathrm{SiO}_{2}: 114200 \mathrm{H}_{2} \mathrm{O}$, which was quite similar to some compositions reported in the literature [18]. Fumed silica (Aerosil, Degussa), granular sodium

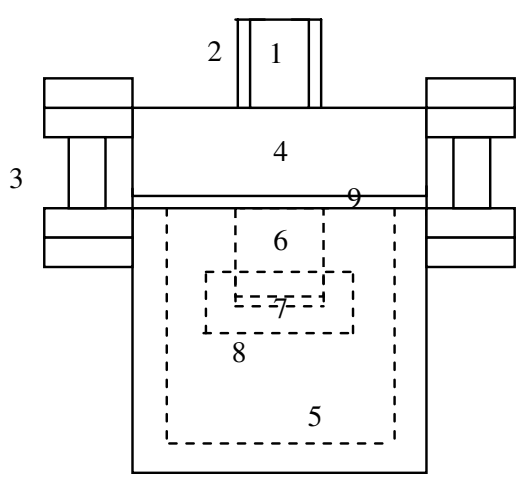

Fig. 1. The substrate heating synthesis system (1: resistance, 2: teflon insulation, 3: bolt and nut, 4: vessel cover, 5: synthesis vessel, 6: cover extension, 7: stainless steel plate, 8: plate holder, 9: teflon gasket). 
aluminate (Riedel-de Haen), anhydrous $\mathrm{NaOH}$ pellets (Carlo Erba), TPAOH solution (Fluka, 20\%) and deionized water were used. After the experiments, the system was cooled immediately, and the stainless steel plates were removed from the device and washed with deionized water.

Scanning electron microscopy (JEOL 5410) and grazing incidence X-ray diffraction (Pananalytical X'Pert Pro) were used to characterize the coatings synthesized on stainless steel plates. X-ray diffraction (XRD) analysis was applied for phase identification. XRD was run at an incidence angle of $1^{\circ}$ with $\mathrm{Cu} K \alpha 1$ radiation. Scanning electron microscopy (SEM) was applied for the determination of the crystal morphology and nature of the coatings.

\section{Results and discussion}

Syntheses of ZSM-5 coatings were carried out under different conditions. The temperatures of the heating resistance and the oil bath were varied between $200-280{ }^{\circ} \mathrm{C}$ and $70-90{ }^{\circ} \mathrm{C}$, respectively. The durations of the syntheses were between 1 and 8 days. Turbidity was generally not observed in the reaction mixtures recovered after the syntheses, indicating that the crystallization in the bulk was suppressed significantly.

The X-ray diffractograms of the samples grown at a heating resistance temperature of $240{ }^{\circ} \mathrm{C}$ after 3,5 and 8 days of synthesis are shown in Fig. 2a-c, respectively. The oil bath temperature was kept at $90{ }^{\circ} \mathrm{C}$ during these experiments. From the XRD analyses, zeolite ZSM-5 was identified as the only crystalline phase in the coatings prepared. The evolution of the crystallinity in the coatings with time can be seen from the diffractograms. The sample prepared after 3 days of synthesis did not exhibit any crystallinity, while the 5 days sample appeared to be crystalline. The synthesis period of 8 days enhanced the intensity of the diffraction peaks characteristic for the ZSM-5 zeolite.

The X-ray diffractograms of the samples grown at a heating resistance temperature of $280{ }^{\circ} \mathrm{C}$ after 3 and 5 days of synthesis are shown in Fig. 3a and b, respectively. The oil bath temperature was again kept at $90{ }^{\circ} \mathrm{C}$. Under these conditions, the evolution of ZSM-5 coatings started earlier. After 3 days of synthesis, the coating was already crystalline. A thicker ZSM-5 coating could be prepared after 5 days of synthesis.

The X-ray diffractogram of the sample prepared by using a heating resistance temperature of $280{ }^{\circ} \mathrm{C}$ after 5 days of synthesis, when the oil bath temperature was kept at $70{ }^{\circ} \mathrm{C}$, is shown in Fig. 4. At this lower temperature of the reaction mixture, it was not possible to obtain a ZSM-5 coating, and the crystalline phase present in this sample was identified as zeolite $\mathrm{P}$. This result may be regarded as surprising since an organic template and only a quite low amount of aluminum were present in the reaction mixture. It appears that the preparation of ZSM-5 coatings from the composition used in this study becomes difficult when the bulk of the synthesis solution is kept at relatively low temperatures.
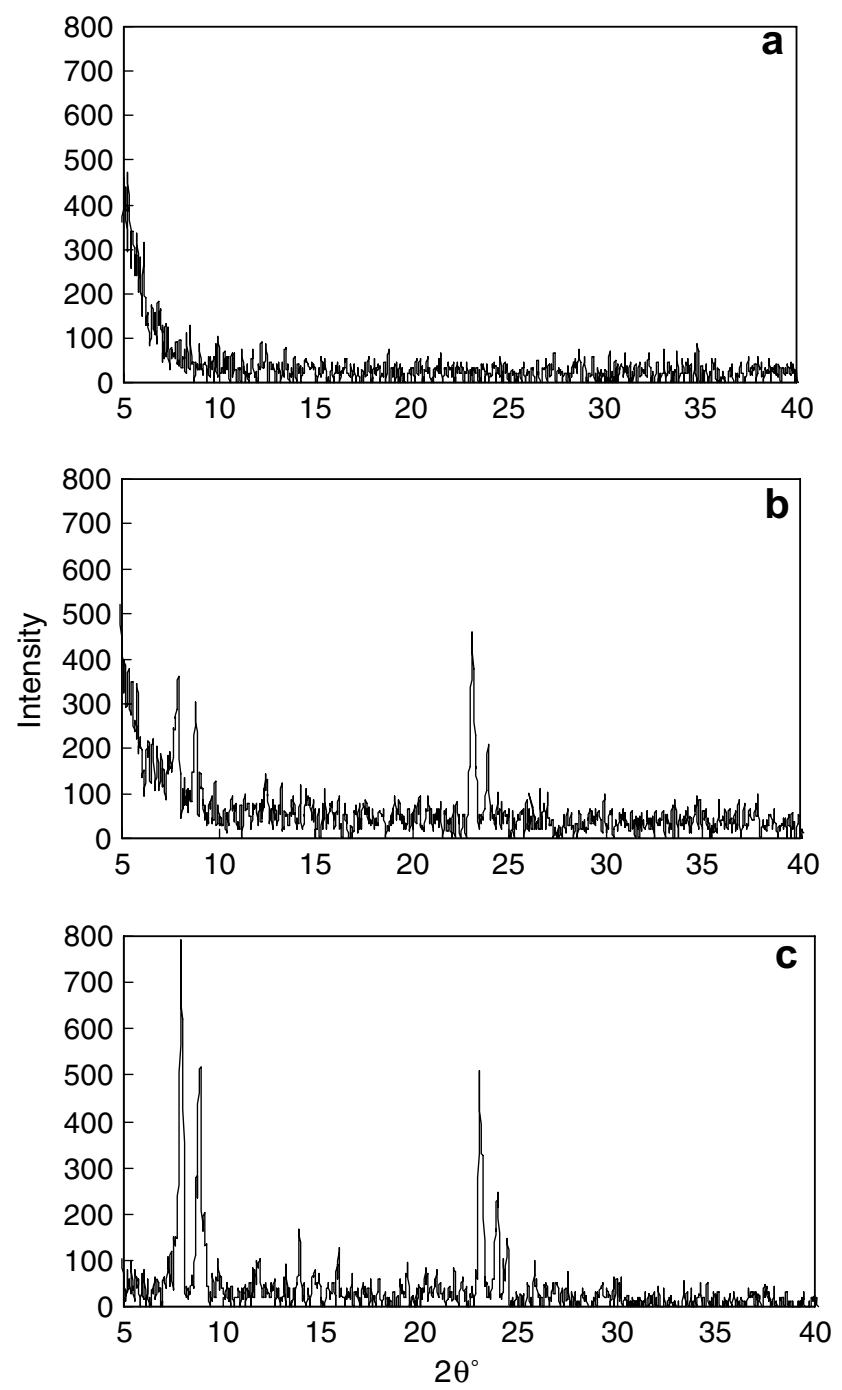

Fig. 2. X-ray diffractograms of the coatings prepared at a resistance temperature of $240{ }^{\circ} \mathrm{C}$ after (a) 3, (b) 5 and 8 days of synthesis when the oil bath was kept at $90^{\circ} \mathrm{C}$.

Some changes were observed in the orientation of the coatings with respect to the synthesis conditions used. At the lower substrate temperature of $240{ }^{\circ} \mathrm{C}$, the diffraction peaks of $\{101\} /\{011\}$ and $\{200\} /\{020\}$ became relatively stronger in comparison to other peaks as the synthesis duration was extended. At the higher substrate temperature of $280{ }^{\circ} \mathrm{C}$, the relative significance of the diffraction peak $\{101\} /\{011\}$ increased further while the peak $\{200\} /\{020\}$ became weaker, which was more pronounced for the longer synthesis duration. The higher difference in temperature between the substrate and synthesis solution seemed to favor the growth of $\{h 0 h\}$-oriented films.

The variation of the mass and thickness of the coatings prepared under different synthesis conditions is summarized in Table 1. When zeolite coatings of somewhat open natures are taken into consideration, it is difficult to represent their thickness by a single value. One approach may be using a mass equivalent thickness for these coatings, which may be determined as (mass of zeolite deposited per coated 


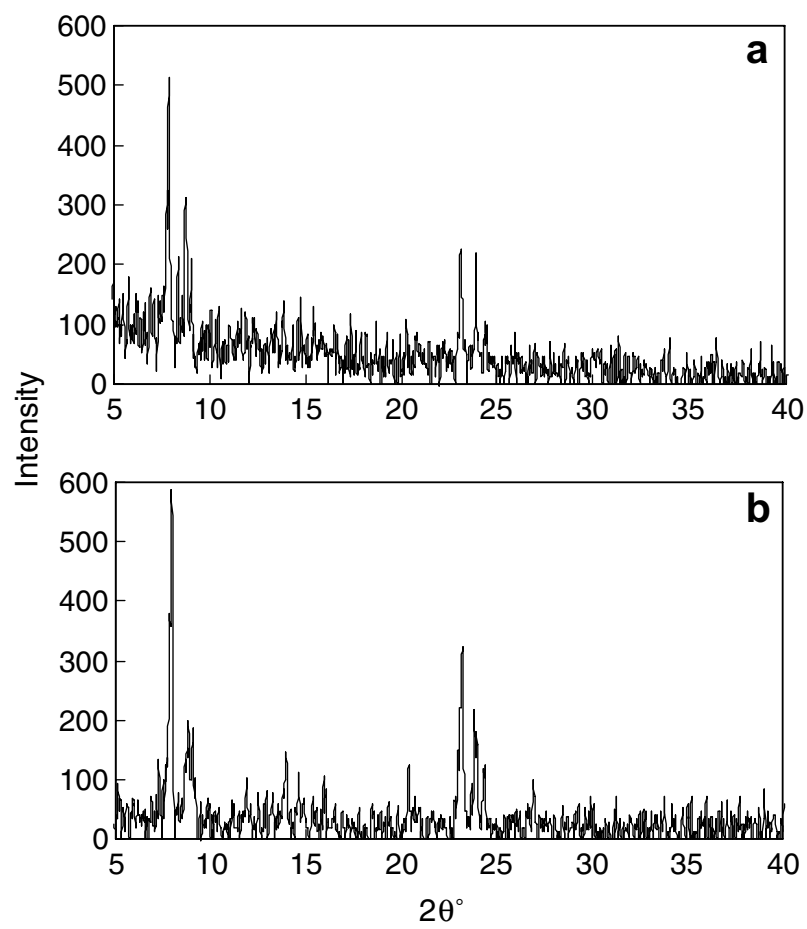

Fig. 3. X-ray diffractograms of the coatings prepared at a resistance temperature of $280^{\circ} \mathrm{C}$ after (a) 3 and (b) 5 days of synthesis when the oil bath was kept at $90^{\circ} \mathrm{C}$.

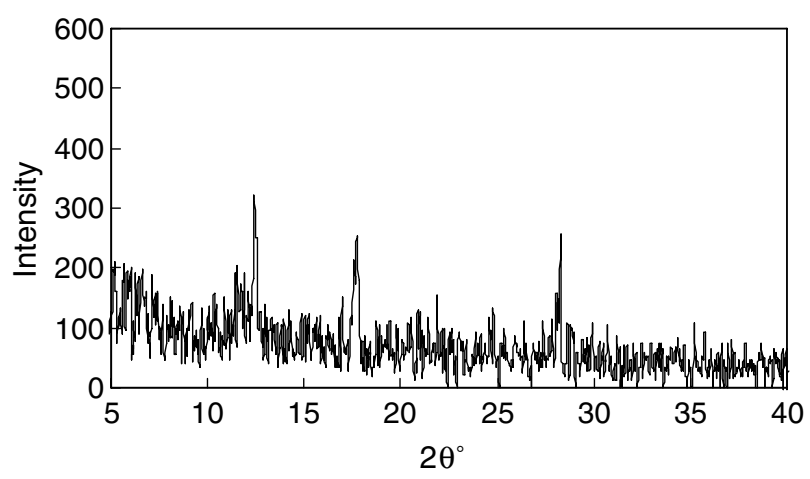

Fig. 4. X-ray diffractogram of the coating prepared at a resistance temperature of $280^{\circ} \mathrm{C}$ after 5 days of synthesis when the oil bath was kept at $70{ }^{\circ} \mathrm{C}$.

area of substrate)/(density of zeolite). The other one is to use the actual coating thickness, which may be determined by taking the average of the values obtained from a num- ber of thickness measurements performed. In this study, the actual coating thickness was measured by a digital micrometer. The void fraction of the coating was determined as 1 -(equivalent thickness/actual thickness). At relatively short synthesis durations and low resistance temperatures, the coatings were amorphous in nature, which could be transformed into crystalline ZSM- 5 by adjusting the synthesis parameters. The highest amount of zeolite mass obtained per area was equal to $3.3 \mathrm{mg} / \mathrm{cm}^{2}$, which corresponded to the highest actual coating thickness of about $38 \mu \mathrm{m}$. Under the conditions used (temperatures of $90{ }^{\circ} \mathrm{C}$ for the oil bath and $240-280{ }^{\circ} \mathrm{C}$ for the heating resistance), the mass and thickness of the zeolite coatings started to increase significantly after crystallinity evolved. The increase made in the resistance temperature also led to an enhancement in the mass and thickness obtained but this improvement was also much more pronounced at 5 days of synthesis. The actual thicknesses of the coatings synthesized at longer times were observed to be about two folds higher than the equivalent thicknesses, indicating the presence of significant amount of void regions in the coatings. The difference between the measured and estimated thickness values generally increased for thicker coatings.

Figs. 5-7a and $\mathrm{b}$ depict the SEM images of the samples prepared after 3, 5 and 8 days of synthesis, respectively, when a resistance temperature of $240^{\circ} \mathrm{C}$ and an oil bath temperature of $90^{\circ} \mathrm{C}$ were used. The XRD results indicated that the coating prepared after 3 days of synthesis was amorphous in nature. From Fig. 5, it seems that the small ZSM-5 crystalline particles begin to form from the amorphous material covering the substrate at this period of time. It is a common observation in the preparation of zeolite coatings that first an amorphous layer is formed on the substrate, which is later transformed into growing crystals. Fig. 6 shows the ZSM-5 layer formed when the synthesis duration was extended to 5 days. The crystals generally had sharp edges and corners with prismatic morphology. Some rectangular twinned crystals could also be observed within this sample. It may be seen from Fig. 7a that a change started to take place in the morphology of the ZSM-5 crystals forming the coating after 8 days of synthesis. Small spherical particles, some of which resemble lathshaped ZSM-5 crystals were observed to form on the twinned crystals (disc intergrowths). It is well-known that MFI-type zeolite crystals may have different forms, such

Table 1

Mass and thickness of the coatings prepared at an oil bath temperature of $90{ }^{\circ} \mathrm{C}$

\begin{tabular}{llllll}
\hline $\begin{array}{l}\text { Resistance temperature } \\
\left({ }^{\circ} \mathrm{C}\right)\end{array}$ & $\begin{array}{l}\text { Synthesis duration } \\
(\text { days })\end{array}$ & $\begin{array}{l}\text { Coating mass } \\
\left(\mathrm{mg} / \mathrm{cm}^{2}\right)\end{array}$ & $\begin{array}{l}\text { Actual coating thickness } \\
(\mu \mathrm{m})\end{array}$ & $\begin{array}{l}\text { Equivalent coating thickness } \\
(\mu \mathrm{m})\end{array}$ & $\begin{array}{l}\text { Void } \\
\text { fraction }\end{array}$ \\
\hline 200 & 3 & $0.1^{\mathrm{a}}$ & - & - \\
240 & 3 & $0.2^{\mathrm{a}}$ & - & - & - \\
280 & 3 & 0.5 & 4.0 & 2.9 & - \\
240 & 5 & 1.7 & 12.0 & 9.7 & 0.28 \\
240 & 8 & 2.7 & 38.0 & 15.3 & 0.20 \\
280 & 5 & 3.3 & 18.8 & 0.43 \\
\hline
\end{tabular}

${ }^{\text {a }}$ The coating is not crystalline. 


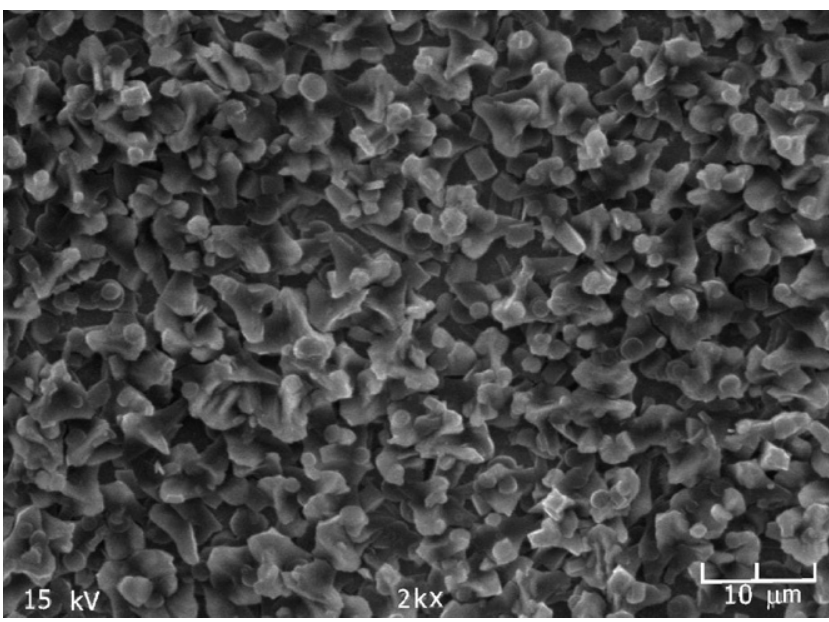

Fig. 5. SEM picture of the coating prepared after 3 days of synthesis when a resistance temperature of $240{ }^{\circ} \mathrm{C}$ and an oil bath temperature of $90{ }^{\circ} \mathrm{C}$ were used.

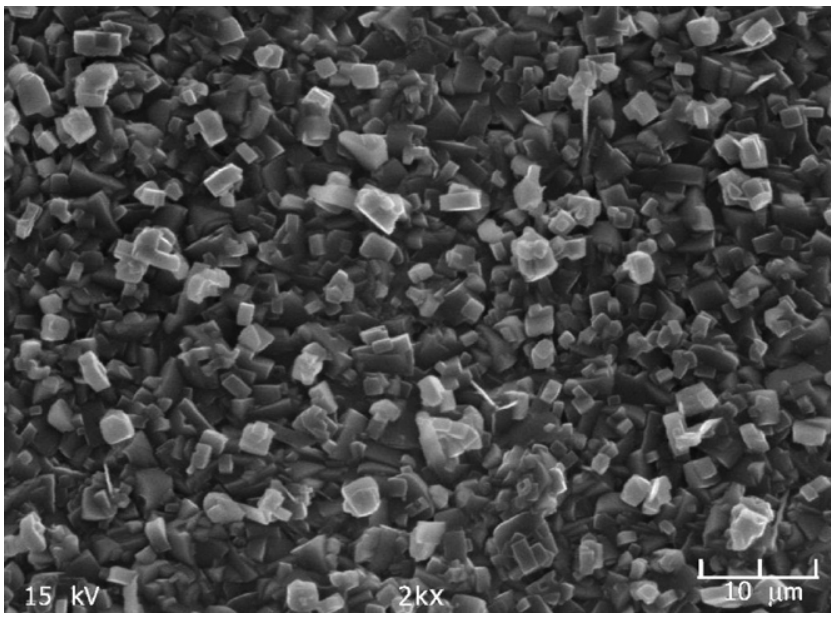

Fig. 6. SEM pictures of the coating prepared after 5 days of synthesis when a resistance temperature of $240{ }^{\circ} \mathrm{C}$ and an oil bath temperature of $90{ }^{\circ} \mathrm{C}$ were used.

as spheres, rods, hexagonal disks, etc., depending on the synthesis conditions [18]. The small particles may indicate the formation of new nuclei. This suggests that ZSM-5 nuclei may have still been forming after 8 days of synthesis, in case a different phase, which could not be detected by $\mathrm{XRD}$, was not emerging. Fig. $7 \mathrm{~b}$ shows the side view (with a tilt of $15^{\circ}$ ) of the continuous coating prepared after 8 days of synthesis. A film thickness of about $27 \mu \mathrm{m}$ was determined by a micrometer. The SEM picture also indicated a similar coating thickness. The crystals were highly intergrown and strongly attached to the metal surface.

Figs. 8 and 9 depict the SEM pictures of the samples prepared after 3 and 5 days of synthesis, respectively, when a resistance temperature of $280^{\circ} \mathrm{C}$ and an oil bath temperature of $90{ }^{\circ} \mathrm{C}$ were used. It may be observed from the figures that as the resistance temperature was increased, lath-shaped crystals became dominant in the samples prepared after both 3 and 5 days of synthesis. The crystal
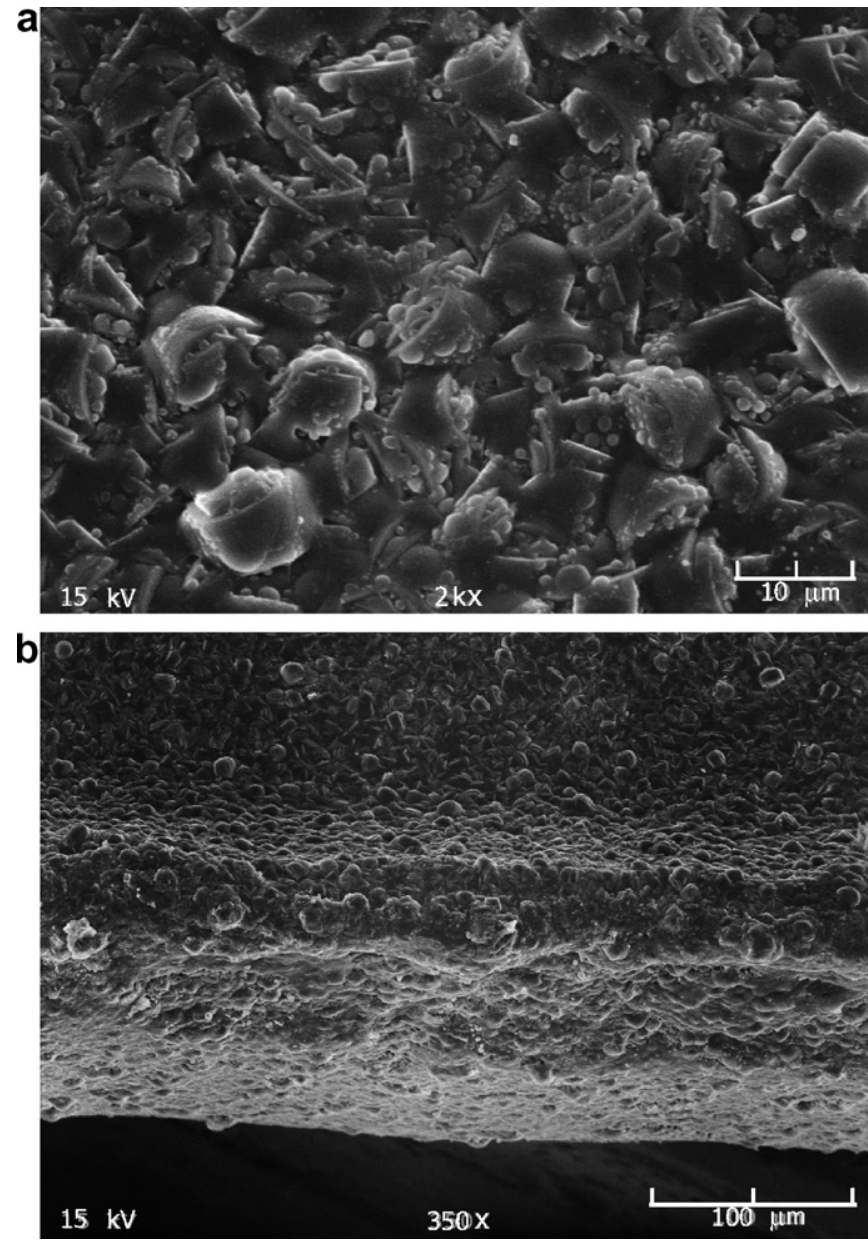

Fig. 7. (a) Top and (b) side views taken by SEM for the coating prepared after 8 days of synthesis when a resistance temperature of $240^{\circ} \mathrm{C}$ and an oil bath temperature of $90{ }^{\circ} \mathrm{C}$ were used.

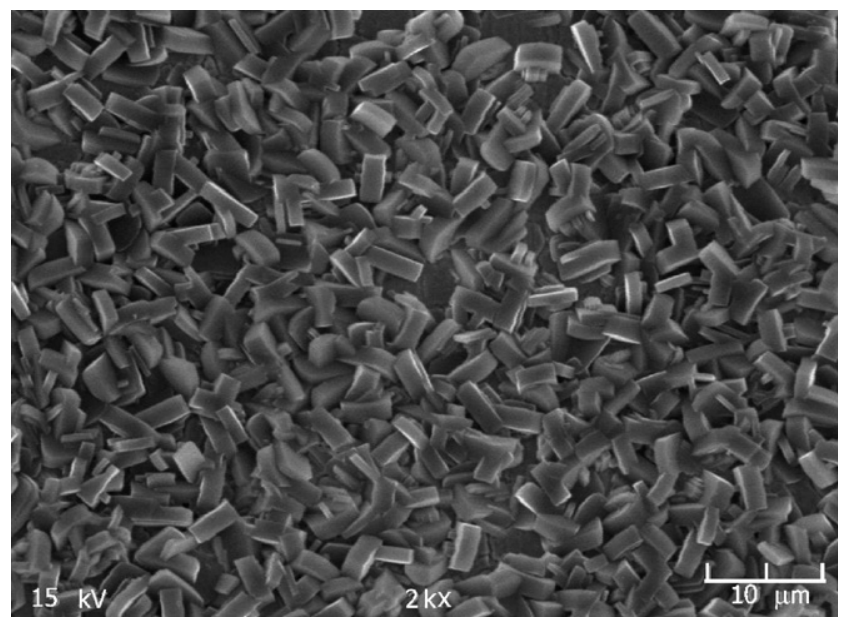

Fig. 8. SEM picture of the coating prepared after 3 days of synthesis when a resistance temperature of $280^{\circ} \mathrm{C}$ and an oil bath temperature of $90^{\circ} \mathrm{C}$ were used.

size increased notably as the synthesis duration was extended. The actual thickness of the coating prepared after 5 days of synthesis, which seemed to contain the highest amount of void regions according to the measurements 


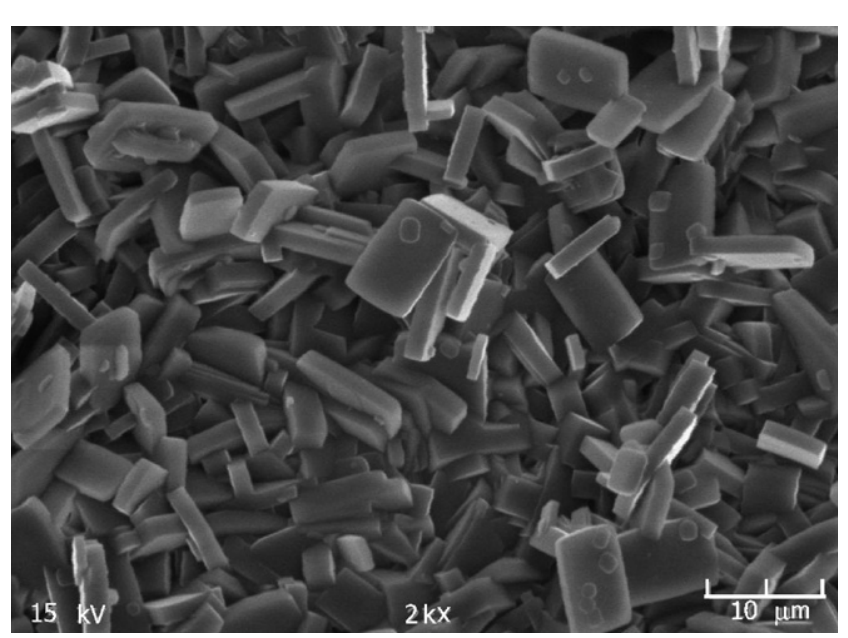

Fig. 9. SEM picture of the coating prepared after 5 days of synthesis when a resistance temperature of $280^{\circ} \mathrm{C}$ and an oil bath temperature of $90{ }^{\circ} \mathrm{C}$ were used.

performed by a micrometer, was equal to about $38 \mu \mathrm{m}$. The void fraction in the ZSM-5 coatings generally increased concomitantly with the increase in thickness and could attain values as high as 0.5 .

In a previous study where quite thick zeolite A coatings were prepared by the substrate heating method, the surface of the coating became corrugated for increased thicknesses resulting in a tree-like growth [12]. In this study, although a tree-like growth could not be observed for the synthesis conditions used, significant amount of non-zeolite void regions were observed. The coatings prepared by the substrate heating method exhibit differences in their nature originating from their growth under a thermal gradient. At the beginning of synthesis when the substrate is still empty, the reaction occurs at the solution-metal interface at a relatively higher temperature. As the thickness of the layer covering the substrate increases, the temperature of the interface may decrease to some degree, resulting in an increase in the ratio of the rate of nucleation with respect to the rate of crystal growth, which in turn may lead to a decrease in the apparent film density with increasing equivalent thickness. The enhancement of the ratio of the rate of nucleation with respect to the rate of crystal growth has been previously shown to lead to the formation of coatings with higher void fractions [19].

The substrate heating method is suitable for the preparation of MFI-type coatings since the synthesis may be carried out under atmospheric pressure at low reaction temperatures $<100^{\circ} \mathrm{C}$. ZSM-5 membranes could be obtained from a composition similar to that used in this study only at a quite high reaction temperature of $175^{\circ} \mathrm{C}$ when conventional syntheses were performed [20]. Additionally, with substrate heating, zeolite synthesis may be manipulated easily due to the possibility of adjusting the metal temperature independently from the temperature of the reaction mixture. This is especially useful for preparing thicker coatings at relatively short synthesis durations. The preparation of uniform and more open ZSM-5 coatings with significant void fraction is also possible. Such coatings provide continuous paths for heat and mass transfer. The latter may signify a higher effective diffusion coefficient and also a higher stability of the coating during applications involving adsorption and desorption.

The substrate heating method may also be a powerful tool for shedding light on the mechanism of zeolite synthesis. Despite years of concerted effort, the mechanism of zeolite synthesis still remains largely a mystery. How the composition and structure of the liquid phase relates to the framework structure of the crystalline solid that forms from it is still an important question that needs to be answered. The method, allowing zeolite film growth, while avoiding bulk crystallization, may provide a solution phase that is rich in the nascent building blocks at a sufficiently low temperature to avoid being contaminated with the crystalline product, an ideal system for the characterization of the zeolite growth medium.

The results obtained in this study for the syntheses carried out at different substrate and reaction mixture temperatures have already given some implications about zeolite film formation. It was observed that the substrate temperature rather affected the rate of crystallization while the solution temperature had more impact on the zeolite framework structure that formed, implying that the growth mechanism may be an outcome of what already exists in the solution, rather than being driven by any "seeding" at the solid/solution interface. There were also indications that before the formation of crystalline ZSM-5, an X-ray amorphous precursor material covered the substrate. This observation may favor the point of view that amorphous precursor particles first aggregate and then convert to ZSM-5. A more detailed investigation is obviously warranted on this issue.

\section{Conclusions}

1. The substrate heating method could be used to prepare ZSM-5 zeolite coatings on metal substrates at reaction mixture temperatures below $100{ }^{\circ} \mathrm{C}$. Uniform and open ZSM-5 films of up to about $40 \mu \mathrm{m}$ thickness could be obtained after a few days of syntheses.

2. The mass of the coatings increased with the substrate temperature and the duration of synthesis. The main effect of the substrate temperature was on the rate of crystallization, rather than the zeolite framework structure formed.

3. The formation of zeolite $\mathbf{P}$ was observed when the temperature of the reaction mixture was decreased to $70^{\circ} \mathrm{C}$, indicating that the reaction mixture temperature may have more impact on the framework structure of the zeolite product.

4. It was possible to manipulate the texture of the zeolite coating by varying the synthesis conditions. Increasing the substrate temperature and/or the synthesis duration led to the formation of larger crystals as well as thicker films, which generally had larger void fractions. The 
morphology of the crystals was also affected by the synthesis duration and temperature.

5. Substrate heating may provide a suitable method for the elucidation of the mechanism of zeolite crystallization.

\section{References}

[1] C.S. Tsay, A.S.T. Chiang, AIChE J. 46 (2000) 616.

[2] F. Jareman, J. Hedlund, Micropor. Mesopor. Mater. 82 (2005) 201.

[3] H.P. Calis, A.W. Gerritsen, C.M. Van den Bleek, C.H. Legein, J.C. Jansen, H. Van Bekkum, Can. J. Chem. Eng. 73 (1993) 120.

[4] I. Yuranov, A. Renken, L. Kiwi-Minsker, Appl. Catal. A 281 (2005) 55.

[5] S. Mintova, T. Bein, Micropor. Mesopor. Mater. 50 (2001) 159.

[6] M. Tatlier, S..B. Tantekin-Ersolmaz, A. Erdem-Şenatalar, Micropor. Mesopor. Mater. 27 (1999) 1.

[7] J. Sterte, S. Mintova, G. Zhang, B.J. Schoeman, Zeolites 18 (1997) 387.

[8] Z. Lai, G. Bonilla, I. Diaz, J.G. Nery, K. Sujaoti, M.A. Amat, E. Kokkoli, O. Terasaki, R.W. Thompson, M. Tsapatsis, D.G. Vlachos, Science 300 (2003) 456.
[9] F.-Z. Zhang, M. Fuji, M. Takahashi, J. Am. Ceram. Soc. 88 (2005) 2307.

[10] G.T.P. Mabande, S. Ghosh, Z. Lai, W. Schwieger, M. Tsapatsis, Ind. Eng. Chem. Res. 44 (2005) 9086.

[11] J. Choi, S. Ghosh, Z. Lai, M. Tsapatsis, Angew. Chem. Int. Ed. 45 (2006) 1154.

[12] A. Erdem-Şenatalar, M. Tatlier, M. Ürgen, Micropor. Mesopor. Mater. 32 (1999) 331.

[13] O. Öhrman, J. Hedlund, V. Msimang, K. Möller, Micropor. Mesopor. Mater. 78 (2005) 199.

[14] E.V. Rebrov, G.B.F. Seijger, H.P.A. Calis, M.H.J.M. de Croon, M. Van den Bleek, H.P.A. Calis, Appl. Catal. A 206 (2001) 125.

[15] M.A. Ulla, R. Mallada, J. Coronas, L. Gutierez, E. Miro, J. Santamaria, Appl. Catal. A 253 (2003) 257.

[16] A. Erdem-Şenatalar, K. Öner, M. Tatlier, Stud. Surf. Sci. Catal. 154 (2004) 667.

[17] J.C. Jansen, D. Kaschiev, A. Erdem-Şenatalar, Stud. Surf. Sci. Catal. 85 (1994) 215.

[18] T. Ban, H. Mitaku, C. Suzuki, J. Matsuba, Y. Ohya, Y. Takahashi, J. Cryst. Growth 274 (2005) 594.

[19] M. Tatlier, Fractals 11 (2003) 77.

[20] Y. Yan, M.E. Davis, G.R. Gavalas, Ind. Eng. Chem. Res. 34 (1995) 1652. 